\title{
La Renaissance décentrée, "Actes du Colloque de Genève, 28-29 septembre 2006», publiés sous la direction de Frédéric Tinguely
}

\section{Dario Cecchetti}

\author{
(2) OpenEdition \\ Journals \\ Edizione digitale \\ URL: http://journals.openedition.org/studifrancesi/7860 \\ DOI: $10.4000 /$ studifrancesi.7860 \\ ISSN: 2421-5856

\section{Editore} \\ Rosenberg \& Sellier

\section{Edizione cartacea} \\ Data di pubblicazione: 1 juillet 2009 \\ Paginazione: $378-379$ \\ ISSN: 0039-2944

\section{Notizia bibliografica digitale} \\ Dario Cecchetti, «La Renaissance décentrée, «Actes du Colloque de Genève, 28-29 septembre 2006», \\ publiés sous la direction de Frédéric Tinguely», Studi Francesi [Online], 158 (LIII | II) | 2009, online dal 30 \\ novembre 2015, consultato il 09 janvier 2021. URL: http://journals.openedition.org/studifrancesi/7860 \\ ; DOI: https://doi.org/10.4000/studifrancesi.7860
}

Questo documento è stato generato automaticamente il 9 janvier 2021.

\section{cc) (†) $\odot$}

Studi Francesi è distribuita con Licenza Creative Commons Attribuzione - Non commerciale - Non opere derivate 4.0 Internazionale. 


\title{
La Renaissance décentrée, «Actes du Colloque de Genève, 28-29 septembre 2006», publiés sous la direction de Frédéric Tinguely
}

\author{
Dario Cecchetti
}

\section{NOTIZIA}

La Renaissance décentrée, «Actes du Colloque de Genève, 28-29 septembre 2006», publiés sous la direction de Frédéric tinguely, Genève, Droz, 2008 ( «Travaux d'Humanisme et Renaissance», $\left.\mathrm{n}^{\circ} \mathrm{CDXL}\right)$, pp. 224.

1 Il Convegno ginevrino di cui sono pubblicati gli Atti riprende una tematica resa celebre dal capolavoro di uno dei grandi maestri dell'école de Genève, Georges Poulet (Les Métamorphoses du cercle, Paris, Flammarion, 1961), che ripercorreva lungo i secoli la storia dei cambiamenti di senso del grande emblema del centro e della sfera. Ora, se il saggio di Poulet studiava il long transfert de centralité secondo una prospettiva diacronica di vari secoli, il presente Convegno ha concentrato l'attenzione sul Cinquecento.

2 I contributi qui offerti sono i seguenti: Isabelle PANTIN, Faux centres, vrais centres, centres multiples: la résistance au décentrement dans les débats des astronomes de la Renaissance (pp. 15-32); Antonella DEL PRETE, Une sphère infinie dont le centre est partout et la circonférence nulle part. L'omnicentrisme chez Giordano Bruno (pp. 33-47); Marie-Christine GOMEZ-GÉRAUD, «Le Bouquet sacré» de Jean Boucher: une poétique du décentrement (pp. 49-59); Frédéric TINGUELY, Le monde multipolaire des missionaires jésuites (pp. 61-72); Frédéric ELSIG, La notion de 'centre' dans la peinture de la Renaissance (pp. 73-82); Victor I. SтогснітA, Comment goûter un tableau? (pp. 83-103); Ulrich LANGER, La mise en question du 'milieu' éthique chez Valla, Vives et Montaigne (pp. 105-118); Patricia EICHEL-LOJKINE, "Écoutons la partie adverse». Dispositifs du décentrement dans la satire humaniste: l'exemple des «Lettres des hommes 
obscurs» (pp. 119-137); Daniela SOLFAROLI CAMILlocci, La critique paradoxale de la centralité de Rome dans le discours satirique des 'hérétiques italiens' (pp. 139-153); Marie-Luce DEMONET, Les textes et leur centre à la Renaissance: une structure absente? (pp. 155-173); Emmanuel NAYA, Périphérie et point centrique: la crise de la signification chez Rabelais (pp. 175-192); Dominique BRANCHER, L'anthropocentrisme à l'épreuve du végétal: botanique sensible et subversion libertine (pp. 193-214).

Il curatore Frédéric Tinguely, nella sua Ouverture (Les métamorphoses du centre, pp. 9-13), sottolinea come l'intero volume «sia consacrato a descrivere il modo in cui il Rinascimento europeo ha decentrato la sua visione del mondo, al modo in cui si è esso stesso decentrato; come non abbia preso globalmente posizione a favore di un decentramento degli studi sul Rinascimento, anche se le due prospettive possono intersecarsi, in particolare nell'analisi dei contatti tra l'Europa e il resto del mondo sulle soglie della modernità» (p. 10). Come appare dalla lista delle comunicazioni, troviamo delle analisi precise sulla cosmologia, sulla filosofia e sulla letteratura umanistica, non solo, ma anche sulla geografia, sulla botanica, sulla pittura e, infine, sulla polemica religiosa. Nei vari saggi la nozione di centro si trova secondo differenti accezioni. Anzitutto, la nozione di centro è intesa in termini strettamente geometrici, e nella sua accezione più strettamente letterale la centralità si definisce sempre in riferimento al cerchio o alla sfera. Quando l'allargarsi degli orizzonti geografici detronizza Gerusalemme dalla sua posizione privilegiata di ombelico del mondo abitato, quando il sistema di Copernico sloggia la terra dal cuore dell'universo, questo primo genere di centralità si trova abolito. Due interventi di straordinario interesse (Elsig, Stoichita) dimostrano come questo mutamento della percezione e della concezione di centralità globale dello spazio influisca profondamente sulla costruzione pittorica rinascimentale. Per quanto concerne la letteratura «l'identificazione di una centralità oggettiva diventa più delicata, se non pericolosa: a meno di considerare il calligramma (il che ci riporta alle arti plastiche), occorre tenere presente che il testo si spazializza soltanto per meglio spiegarsi nel 'tempo' della lettura» (p. 11). A un livello metaforico la nozione di centro rimanda anche a un punto privilegiato dello spazio reale o di una configurazione più astratta. Appare evidente, dalle pagine stimolanti $\mathrm{e}$ utili di questi Atti, come «moltiplicando i decentramenti, la cultura del Rinascimento provochi una proliferazione di nuovi centri e di nuove concezioni della centralità. Più di un secolo prima della famosa 'crisi della coscienza europea' i decentramenti rinascimentali, nella loro stessa diversità, scuotono l'universo mentale degli Europei e producono effetti di pensiero propizi all'emergere del relativismo» (p. 13). 